\title{
A PRÁtICA DO PROFISSIONAL DE EDUCAÇÃO FÍSICA COM ÊNFASE NAS PESSOAS IDOSAS: AÇÕES EMERGENTES NAS POLÍTICAS PÚBLICAS
}

\section{ARTIGO DE REVISÃO}

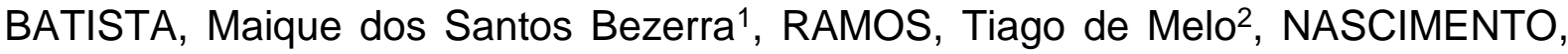
Mauricio Santana do ${ }^{3}$

BATISTA, Maique dos Santos Bezerra. RAMOS, Tiago de Melo. NASCIMENTO, Mauricio Santana do. A prática do profissional de educação física com ênfase nas pessoas idosas: ações emergentes nas políticas públicas. Revista Científica Multidisciplinar Núcleo do Conhecimento. Ano: 06, Ed. 08, Vol. 02, pp. 119-130. Agosto 2021. ISSN: 2448-0959, Link de acesso: https://www.nucleodoconhecimento.com.br/educacao-fisica/profissional-deeducacao, $\quad$ DOI: $\quad 10.32749 /$ nucleodoconhecimento.com.br/educacaofisica/profissional-de-educacao

\section{RESUMO}

Esse artigo aborda reflexões sobre políticas públicas de atenção às pessoas idosas em sociedade correlacionando o aporte da promoção e prevenção da saúde. O entrelaçamento saúde-idoso acompanha o percurso histórico formalizando-se na Constituição Federal Brasileira e Estatuto do Idoso ampliando-se pelo Sistema Único de Saúde. Emerge, desse contexto, a seguinte pergunta disparadora: Que tipo de ações os profissionais de Educação Física estão desempenhando com as pessoas idosas na perspectiva da promoção e prevenção da saúde? O objetivo é analisar

\footnotetext{
${ }^{1}$ Mestre em Ensino das Ciências Ambientais (UFS); Especialista em Psicomotricidade (UCAM); Licenciado em Educação Física (UniAGES); Bacharel em Educação Física (UniAGES).

${ }^{2}$ Doutorando em Ciências da propriedade intelectual (UFS); Mestre em ciências da propriedade intelectual (UFS); Especialista em ciências da educação (Luzofona); Especialista em treinamento e rendimento esportivo (SERYGI); Graduado em Educação Física (AGES).

${ }^{3}$ Discente de graduação em Educação Física.
}

RC: 93534

Disponível em: https://www.nucleodoconhecimento.com.br/educacaofisica/profissional-de-educacao 
que tipos de ações os profissionais de Educação Física estão desempenhando com as pessoas idosas na perspectiva da promoção e prevenção da saúde. Esse artigo é de cunho bibliográfico analítico-exploratório com aprofundamento do assunto em questão. Quanto à abordagem, tem caráter qualitativo por se ater às interpretações dos dados analisados com descrição detalhada sem apresentação de fenômenos estatísticos. A busca de dados ocorreu a partir de plataformas digitais sendo: PubMed, Scielo, Google acadêmico considerando as seguintes palavras-chaves: envelhecimento ativo, políticas públicas, saúde, profissional da Educação Física, programas de atenção às pessoas idosas, promoção e prevenção da saúde. Consideraram-se artigos e livros publicados entre o ano de 2010 a 2020. Dos 65 (sessenta e cinco) materiais analisados na busca seletiva 5 (cinco) atenderam plenamente aos ideais de análise da pesquisa. Os dados foram analisados a partir de 5 (cinco) categorias correspondentes aos programas direcionados à saúde das pessoas idosas. As categorias foram agrupadas com base nesses programas selecionados a partir de relatos de experiências de profissionais atuantes que materializaram e discutiram os resultados em artigos científicos. A pesquisa mostrou a importância do trabalho coletivo na perspectiva da saúde ampliada bem como a necessidade de fomentar políticas de atenção à saúde que considerem a realidade local.

Palavras-Chave: Pessoas Idosas, Políticas de Saúde, Projetos/Programas, Promoção e Prevenção.

\section{INTRODUÇÃO}

O crescimento populacional vem aumentando significativamente nos últimos anos devido à redução das taxas de natalidade e o aumento da expectativa de vida. Destacam-se, nesse cenário, a população idosa ao observar nas projeções etária os dados estatísticos em diferentes variações temporais. Dentro desta perspectiva, é possível prever que o número de habitantes no planeta terra deve chegar a 9,7 bilhões em 2050. O índice da população em 30/10/2020 é de 212.243.470 
habitantes, desse quantitativo $14.18 \%$ da população é representada por pessoas idosas com sessenta e cinco anos ou mais. Na estimativa para o ano de 2060, a população brasileira terá um aumento de $42,62 \%$. No Estado da Bahia, o índice populacional é de 14.947 .490 habitantes, desse número $13,28 \%$ da população está representada por pessoas idosas que, na escala de projeção para o ano de 2060, esse número, aumentará para 33\% da população (IBGE, 2020)

Essas estatísticas refletem a necessidade de projetar a curto, médio e longo prazo, estratégias econômicas, políticas e governamentais para lidar com essa crescente demanda social objetivando garantir a essa população condições dignas para conviver em cidadania com acesso as questões básicas: moradia, segurança, educação, saúde, saneamento básico entre outras. Nessa reflexão, é importante salientar os aspectos que ocasionariam a reforma sanitária. Na década de 1970, deram início à mobilização de diferentes atores sociais responsáveis com a saúde e qualidade de vida da população brasileira para construção de uma proposta que possibilitasse 0 acesso aos serviços de saúde em diferentes regiões do território nacional sem qualquer tipo de discriminação social (CAMARANO; KANSO; FERNANDES, 2016).

O Sistema Único de Saúde (SUS) emerge de um grande acordo entre conservadores de progressistas implementando a saúde na Constituição Federal Brasileira de 1988, como "um direito de todos e dever do estado" (BRASIL, 1988). No contexto social, a partir da constituição e do SUS, as práticas de saúde ganham visibilidade a partir de políticas de promoção da saúde que refletem nos hábitos saudáveis do sujeito, na alimentação, atividade física, bem-estar físico e mental.

O envelhecimento ativo é um marco político da Organização Mundial da Saúde (OMS) conceituado em 2002 como um "processo de otimização das oportunidades de saúde, educação continuada, participação e segurança, de forma a promover qualidade de vida à medida que se envelhece". No tocante, a OMS criou o projeto Cidade Amiga do Idoso (CAl) para orientar as cidades na adaptação dos seus 
ambientes físico, social e político, com a finalidade de favorecer o envelhecimento ativo de qualidade para cada localidade (CAMARANO; KANSO; FERNANDES, 2016).

Após esses fatos supracitados, surge o paradigma do envelhecimento ativo e, em 2013, torna-se uma proposta de política pública nacional participativa. Os profissionais que atuam com pessoas idosas nas políticas de saúde devem desenvolver um trabalho interdisciplinar na perspectiva da saúde ampliada. Entretanto, notam-se que os currículos adotados pelas instituições de formação profissional nessa área são muito fragmentados, o que os levam a enxergar o sujeito apenas como parte, dando ênfase ao agravo à saúde sem inter-relacionar os fatores associados (BATISTA e BATISTA, 2021).

Suscita, nesse cenário, promover ações que reverberem na integralidade que compõem as dimensões do ser humano nos aspectos biopsicossociais. Emerge desse contexto a seguinte pergunta de investigação: Que tipo de ações os profissionais de Educação Física estão desempenhando com as pessoas idosas na perspectiva da promoção e prevenção da saúde? O objetivo desse artigo analisar que tipos de ações os profissionais de Educação Física estão desempenhando com as pessoas idosas na perspectiva da promoção e prevenção da saúde.

O embasamento dessa pesquisa perpassa pelos preceitos enveredados na Política Nacional do Idoso na Lei o․ 8.842 e no Decreto ํo 1.948/96, que garante promover o envelhecimento saudável, manter e melhorar ao máximo a capacidade funcional dos idosos, prevenir e tratar doenças, assegurando que esta população permaneça em seu meio social. Apoia-se, também, no Estatuto do Idoso, criado em 2003, que propõe assegurar os direitos e deveres das pessoas idosas para melhor convivência em cidadania (CAMARANO; KANSO; FERNANDES, 2016).

Não obstante, observam-se que três conceituações se associam ao envelhecimento: a idade cronológica, os aspectos biológicos e a dimensão social. $\mathrm{Na}$ idade cronológica destacam-se as relações do tempo com a idade. A Organização das

RC: 93534

Disponível em: https://www.nucleodoconhecimento.com.br/educacaofisica/profissional-de-educacao 
Nações Unidas (ONU) traz como pessoa idosa a partir de 60 anos, em países que estão em desenvolvimento; e, 65 anos ou mais, para países desenvolvidos, pois, a idade, para além de uma questão cronológica, está relacionada às condições sociais do sujeito (VERA; OLIVEIRA, 2018).

Já nos aspectos biológicos, entende-se que envelhecer é um processo de mudança psíquica e física, pois, à medida que vai se prolongando a vida, vamos envelhecendo. Os ciclos de vida sofrem mudanças conforme o estilo de vida adotado pelo sujeito. Pessoas que fumam, consomem bebidas alcoólicas com frequência, usam substâncias que prejudica todo os sistemas do corpo humano ocasionam a longo prazo malefícios a saúde, pois, o corpo vai perdendo sua capacidade funcional (ALCÂNTARA; CAMARANO; GIACOMIN, 2016).

$\mathrm{Na}$ dimensão social, a velhice é um fenômeno complexo com variações no tempo e espaço, entendida como uma fase no ciclo da vida. As conotações atreladas às pessoas idosas caminham para generalização figurativa que apresentam: rugas, cabelos brancos, frágil e sem conteúdo. Esses estereótipos ao mesmo tempo padronizam um perfil e os/as excluem de determinados espaços sociais e tomada de decisões (BOEAUVOIR, 2018). Percebe-se, a partir das categorias supracitadas, que as variantes analisadas nas três dimensões buscam esclarecer pontos de intersecção entre o cronológico-biológico-social da velhice, que corresponde a um único elemento comum: o humano. Nessa compreensão, entende-se que a abordagem multidisciplinar transita pelas interfaces que permeiam as relações de sujeito-ambiente.

As equipes multidisciplinares têm um papel fundamental de promover ações de educação em saúde nos setores públicos e privados. As atividades com tais grupos precisam despertar interesses, curiosidades, mobilização dinâmica, verbalização, entre outros artefatos que considere o grupo como partícipes da aprendizagem a partir desses três pontos: exploratórias, investigativas e reflexivas (OLIVEIRA et al., 2020). Por essa razão, ações precisam estar situadas na realidade atravessada de 
sentidos e significados pautada na dimensão do trabalho que considera a aprendizagem com elo centrado no protagonismo do(a) sujeito(a).

Esse artigo é de natureza bibliográfica, analítico-exploratória com aprofundamento do assunto em questão. Para realização da pesquisa, estruturou-se os uma leitura seletiva, analítica e interpretativa de livros e artigos científicos que versam sobre a temática abordada na tentativa de entender com profundidade o assunto e levantar outros pontos que possam contribuir assim como ser submetidos a uma nova investigação cientifica (GIL, 2008). Quanto à abordagem, tem caráter qualitativo por se ater às interpretações dos dados analisados com descrição detalhada sem apresentação de fenômenos estatísticos.

Os dados foram levantados a partir de plataformas digitais intituladas de: PubMed, Scielo, Google acadêmico. Na investigação, foram consideradas as seguintes palavras-chave: envelhecimento ativo, políticas públicas, saúde, profissional da Educação Física, programas de assistência a pessoas idosas, promoção e prevenção da saúde. Consideraram-se os artigos e livros publicados entre o ano de 2010 a 2020 que estivessem em total consonância com o estudo em questão. Dos 65 (sessenta e cinco) materiais analisados na busca seletiva 5(cinco) atenderam plenamente aos ideais de análise da pesquisa.

Os dados foram analisados a partir de 5 (cinco) categorias correspondentes aos programas direcionados à saúde das pessoas idosas. As categorias foram agrupadas com base nesses programas selecionados a partir de relatos de experiências de profissionais atuantes que materializaram e discutiram os resultados em artigos científicos. Os critérios limitadores dessa seleção foram: Conter pessoas idosas no programa; ter no mínimo um profissional de Educação Física; direcionar propostas de prevenção e/ou promoção da saúde. Foi passível de exclusão artigos que não se enquadravam nessa delimitação criteriosa. Para ilustração e discussão dos resultados, foi sistematizado um quadro síntese contendo os seguintes pontos: a referência bibliográfica; o nome e objetivo do programa analisado; as ações 
desenvolvidas; e profissionais atuantes para situar o leitor sobre as considerações realizadas nesse material.

\section{A PRÁTICA DOS PROFISSIONAIS DA SAÚDE COLETIVA BALIZADAS NAS POLÍTICAS PÚBLICAS}

Os profissionais da saúde coletiva têm um papel fundamental na política de planejar e operacionalizar propostas de educação em saúde promovendo ações de caráter preventivos, de bem-estar e socialização, que considerem a realidade local na reflexão sobre o contexto, o global, o multidimensional e complexo, entrelaçados na vida do sujeito em sociedade (BATISTA e BATISTA, 2021). Na emersão dessa reflexão, foi realizado um mapeamento sistematizado de programas com atenção a saúde das pessoas idosas estruturado no quaro síntese abaixo.

Quadro 1: Mapeamento de Programas Direcionados a Saúde das Pessoas Idosas

\begin{tabular}{|c|c|c|c|}
\hline REFERÊNCIAS & $\begin{array}{l}\text { PROGRAMA/ } \\
\text { OBJETIVO }\end{array}$ & AÇÕES & $\begin{array}{l}\text { PROFISSIONAIS } \\
\text { ATUANTES }\end{array}$ \\
\hline 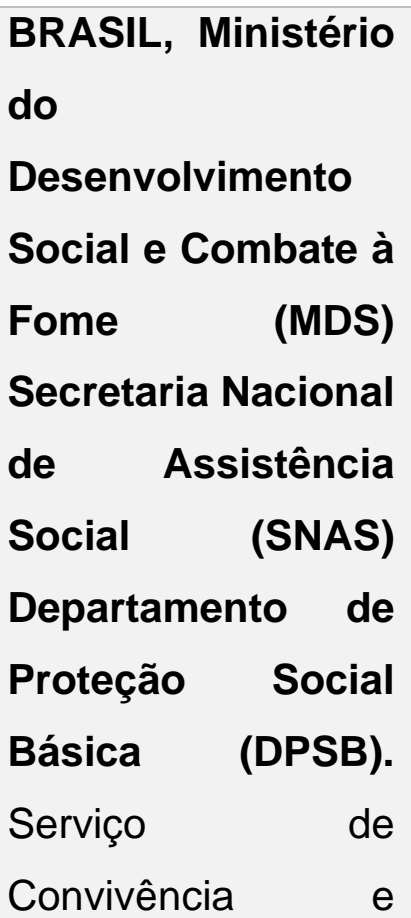 & $\begin{array}{lr}\text {-Geralmente } & \text { esse } \\
\text { programa } & \text { está } \\
\text { associado } & \text { ao } \\
\text { Centro } & \text { de } \\
\text { Referência } & \text { de }\end{array}$ & $\begin{array}{l}\text {-Para crianças até } \\
\text { anos } 5 \text { anos } \\
\text { Sugere-se: } \\
\text { brincadeiras } \\
\text { tradicionais, como } \\
\text { cirandas; teatro } \\
\text { com fantoches; } \\
\text { oficinas de arte com } \\
\text { materiais } \\
\text { recicláveis; oficinas } \\
\text { de massagem; } \\
\text { passeios e visitas a }\end{array}$ & $\begin{array}{l}\text {-Técnico de } \\
\text { referência } \\
\text { Profissional de } \\
\text { nível superior } \\
\text { que integra a } \\
\text { equipe do CRAS } \\
\text { para ser } \\
\text { referência aos } \\
\text { grupos do SCFV. }\end{array}$ \\
\hline
\end{tabular}




\begin{tabular}{|c|c|c|c|}
\hline $\begin{array}{l}\text { Fortalecimento de } \\
\text { Vínculos. Brasília, } \\
2017 .\end{array}$ & $\begin{array}{l}\text {-Favorecer o } \\
\text { desenvolvimento } \\
\text { de atividades } \\
\text { intergeracionais, } \\
\text { propiciando trocas } \\
\text { de experiências e } \\
\text { vivências, } \\
\text { fortalecendo a } \\
\text { respeito, } \\
\text { solidariedade e } \\
\text { os vínculos } \\
\text { familiares a } \\
\text { comunitários }\end{array}$ & 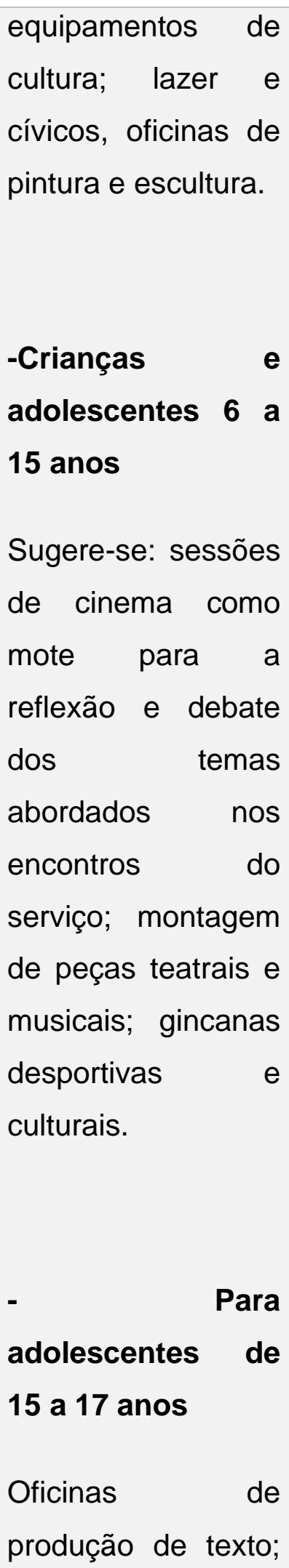 & $\begin{array}{l}\text {-Orientador } \\
\text { social ou } \\
\text { educador social } \\
\text { Função exercida } \\
\text { por profissional } \\
\text { com, } \\
\text { no mínimo, nível } \\
\text { médio de } \\
\text { escolaridade. }\end{array}$ \\
\hline
\end{tabular}




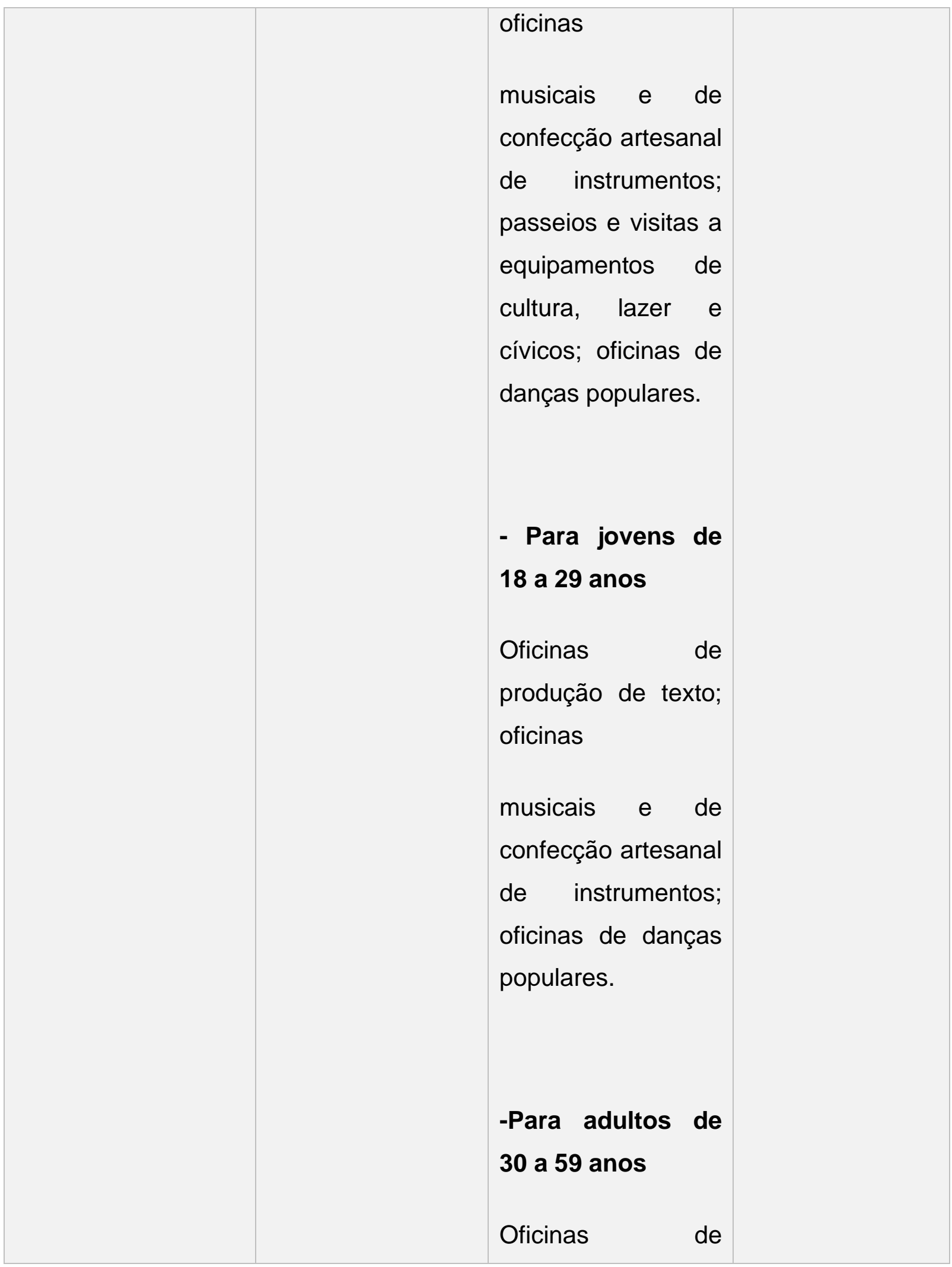

RC: 93534

Disponível em: https://www.nucleodoconhecimento.com.br/educacaofisica/profissional-de-educacao 


\begin{tabular}{|c|c|c|c|}
\hline & & $\begin{array}{l}\text { cidadania, por meio } \\
\text { das quais serão } \\
\text { obtidas informações } \\
\text { sobre acesso e } \\
\text { violação a direitos, } \\
\text { riscos sociais. } \\
\text { Para pessoas } \\
\text { idosas } \\
\text { oficinas de } \\
\text { cidadania, por meio } \\
\text { das quais serão } \\
\text { obtidas informações } \\
\text { sobre acesso a } \\
\text { direitos, riscos } \\
\text { sociais, violência } \\
\begin{array}{l}\text { contra a pessoa } \\
\text { idosa. }\end{array}\end{array}$ & \\
\hline $\begin{array}{l}\text { VAGETTI, Gislaine } \\
\text { Cristina et al. } \\
\text { Associação do } \\
\text { índice de massa } \\
\text { corporal com a } \\
\text { aptidão funcional } \\
\text { de idosas } \\
\text { participantes de } \\
\text { um programa de } \\
\text { atividade }\end{array}$ & $\begin{array}{l}\text {-Pode ser } \\
\text { promovido pela } \\
\text { Secretaria } \\
\text { Municipal de } \\
\text { Esporte e Lazer. }\end{array}$ & $\begin{array}{l}\text {-Competições } \\
\text { esportivas; } \\
\text { atividades de lazer; } \\
\text { atividades físicas e } \\
\text { recreativas; aulas } \\
\text { de ginástica; dança; } \\
\text { danças sentadas; }\end{array}$ & $\begin{array}{l}\text {-Profissionais de } \\
\text { Educação Física } \\
\text { em parceria com } \\
\text { nutricionistas e } \\
\text { acadêmicos de } \\
\text { fisioterapia. }\end{array}$ \\
\hline
\end{tabular}


física. Revista

Brasileira

Geriatria

Gerontologia, 2017.

\section{RIBEIRO, \\ Sheylazarth. \\ FERRAZ, Eduardo \\ Martins. Programa \\ esporte e lazer da \\ cidade: autogestão \\ em \\ foco.}

Corpoconsciência,

Cuiabá-MT. 2016.
-Acontecem em

núcleos, que são o

encontro

agentes sociais e

de

O programa

organiza três 1 (um) ações:

participantes em

um espaço da

comunidade.

-Construir

mecanismos

A entidade de controle social;

O conselho gestor;

1(um) pilates;

caminhadas;

festivais de danças;

jogos dos grupos

de idosos; festival

cultural; atividades

alusivas a datas

comemorativas;

intercâmbios

culturais.

e

da

entidades

parceiras;

Encontros com a representante da comunidade no entidade de 


\begin{tabular}{|c|c|c|c|}
\hline & $\begin{array}{l}\text { ampliar o acesso } \\
\text { da população } \\
\text { brasileira a } \\
\text { atividades de } \\
\text { esporte e lazer. }\end{array}$ & $\begin{array}{l}\text { formato de oficina } \\
\text { atendo a todos os } \\
\text { públicos. }\end{array}$ & $\begin{array}{l}\text { controle social; } \\
\text { 1(um) } \\
\text { representante } \\
\text { dos } \\
\text { coordenadores } \\
\text { de núcleo; } \\
1 \text { (um) } \\
\text { representante } \\
\text { dos } \\
\text { agentes sociais; } \\
1 \text { (um) } \\
\text { representante da } \\
\text { comunidade. }\end{array}$ \\
\hline $\begin{array}{l}\text { FERREIRA, } \\
\text { Marielle Cristina } \\
\text { Gonçalves et al. } \\
\text { Programa } \\
\text { Academia Carioca } \\
\text { da Saúde: } \\
\text { Cotidiano, lazer e } \\
\text { saúde de } \\
\text { idosos. Revista } \\
\text { Brasileira } \\
\text { Geriatria } \\
\text { Gerontologia, v. 23, } \\
\text { n. 6, 2020. }\end{array}$ & $\begin{array}{l}\text {-Academia da } \\
\text { saúde } \\
\\
\\
\\
\text {-Associada a } \\
\text { Clínica de } \\
\text { Estratégia de } \\
\text { Saúde da Família- } \\
\text { ESF }\end{array}$ & $\begin{array}{l}\text { Exercícios físicos } \\
\text { com e sem } \\
\text { aparelhos; } \\
\text { palestras; grupos } \\
\text { de artesanato; } \\
\text { caminhada; dança } \\
\text { de salão; visitas } \\
\text { domiciliares; } \\
\text { passeios culturais e } \\
\text { confraternização } \\
\text { para os } \\
\text { aniversariantes do } \\
\text { mês. }\end{array}$ & $\begin{array}{l}\text { Profissionais da } \\
\text { saúde } \\
\text { (nutricionista, } \\
\text { Psicólogos, } \\
\text { fisioterapeuta, } \\
\text { Profissionais de } \\
\text { educação física. }\end{array}$ \\
\hline
\end{tabular}




\begin{tabular}{|c|c|c|c|}
\hline & $\begin{array}{l}\text {-Promover a saúde } \\
\text { e prevenir } \\
\text { doenças, } \\
\text { adoção de } \\
\text { estilo de um } \\
\text { saudável. }\end{array}$ & & \\
\hline $\begin{array}{l}\text { FERRARINE, } \\
\text { Rosane de Fátima. } \\
\text { Terceira idade e } \\
\text { movimento, } \\
\text { Campina Grande } \\
\text { do Sul, } 2011 .\end{array}$ & $\begin{array}{l}\text {-Terceira Idade e } \\
\text { Movimento } \\
\text {-Secretarias de } \\
\text { Saúde } \\
\text {-Garantir } \\
\text { atendimento } \\
\text { socioeducativo a } \\
\text { grupos da terceira } \\
\text { idade, } \\
\text { assegurando } \\
\text { acesso às políticas } \\
\text { públicas } \\
\text { cidadania. }\end{array}$ & 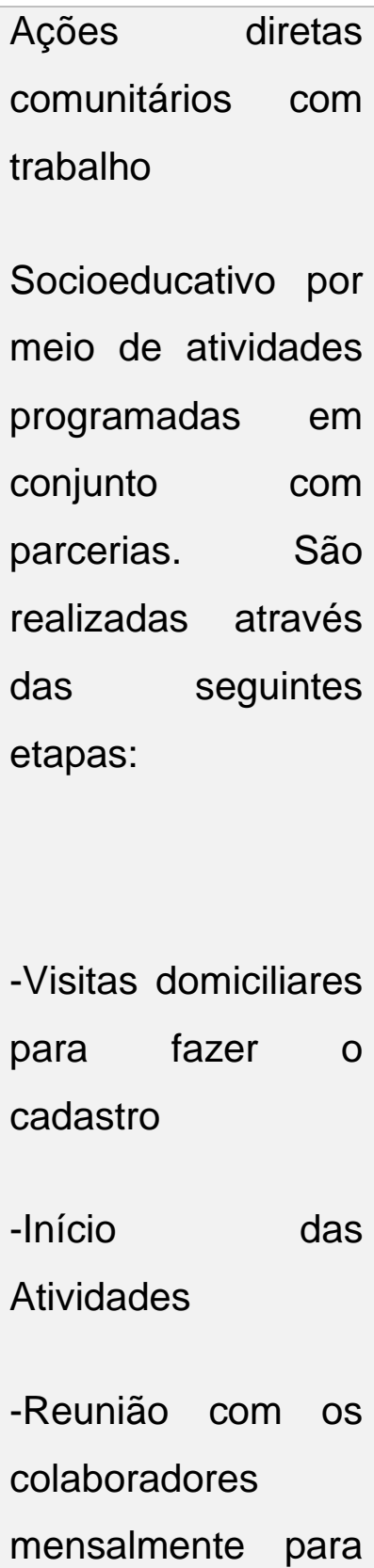 & $\begin{array}{l}\text { Médicos, } \\
\text { Nutricionistas, } \\
\text { Fisioterapeutas } \\
\text { Assistentes } \\
\text { Sociais, } \\
\text { Psicólogos, } \\
\text { Profissionais de } \\
\text { educação física. }\end{array}$ \\
\hline
\end{tabular}




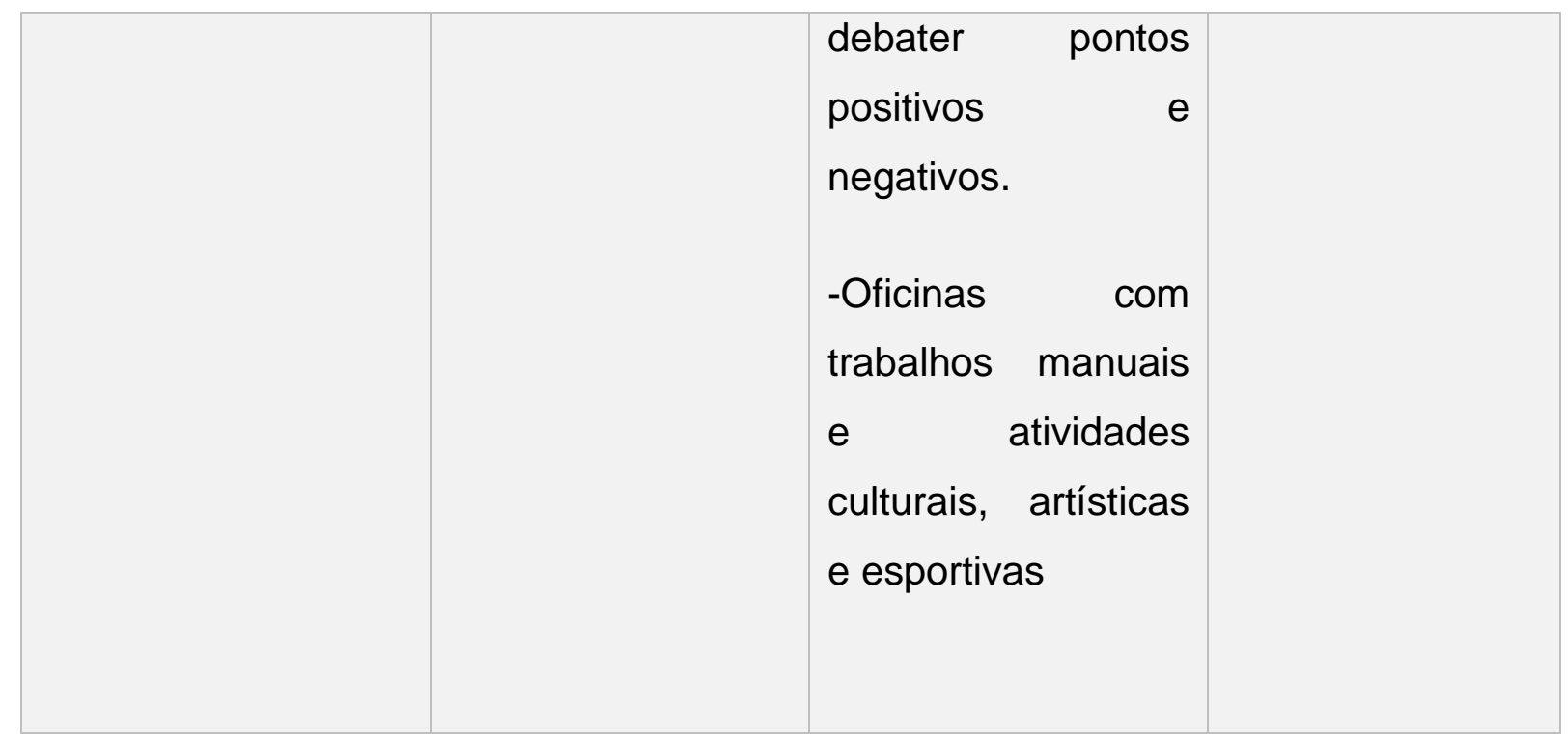

Fonte: elaboração dos autores produzida em 2021.

O mapeamento investigativo possibilitou levantar dados de programas com ênfase na atenção a saúde das pessoas idosas. Ao analisar as categorias elencadas no quadro, percebe-se que na primeira, o Programa Serviço de Convivência e Fortalecimento de Vínculos (SCFV), trata-se de um serviço da Proteção Social Básica do SUAS, regulamentado pela Tipificação Nacional de Serviços Socioassistenciais (Resolução CNAS no 109/2009). Foi reordenado em 2013 por meio da Resolução CNAS no 01/2013. O programa acontece por meio de grupos de faixa etária já citadas no quadro para atender objetivos específicos (BRASIL, 2017).

O programa atinge 30 pessoas por grupo podendo ocorrer todos os dias uma vez na semana ou a cada quinze dias a depender da organização do programa e acontecem em espaços de centro de convivência ou instituição que tenha parceria com assistência social ou vinculada à prefeitura que, também, é uma chave importante para impulsionar o programa. As atividades desempenhadas no programa visam fortalecer os vínculos familiares e comunitários abarcando uma proposta intergeracional que proporciona a troca de experiência com engajamento integrado entre as gerações obtendo novos conhecimentos e respeitando as diferenças do próximo (BRASIL, 2017). 
Na segunda, o Programa Idoso em Movimento, pode acontecer no campo, na cidade, nas praças, parques, centros de convivência, ginásios esportivos e associações de moradores. As ações desempenhadas trazem benefícios à população contribuindo para uma vida mais ativa e autônoma possibilitando reduzir o índice de doenças crônicas não transmissíveis, uso de medicamentos e depressão.

Além disso, por serem desenvolvidas em diversos pontos, as atividades promovem parcerias e construção de vínculos entre os servidores e a população idosa. Assim, percebe-se que promover uma vida mais ativa possibilita aos sujeitos opções de escolhas em aderir ou não a prática de atividades físicas. Entende-se que, ao adotar um estilo de vida mais ativo, consequentemente, haverá uma melhoria da aptidão física e fortalecimento da condição imunológica que reverbera na redução dos agravos a saúde a exemplo das Doenças Crônicas Não Transmissíveis (DNTs) (BATISTA \& BATISTA, 2021).

Na terceira, o Programa esporte e lazer da cidade (PELC), tem convênio com diferentes esferas: prefeitura, instituições federais, governo do estado. Essas entidades são responsáveis por investir em equipamentos e matérias para ser utilizado na efetivação do programa na cidade atendendo até 400 pessoas por núcleo desempenhando atividades já mencionadas no quadro.

Objetiva-se reconstituir conhecimentos e recursos para intervir no processo social desempenhando novas estratégias para promover cultura de esporte e lazer na concepção de novas possibilidades de ensinar e indagar estabelecendo interação com a comunidade na adequação de atividades específicas para o atendimento de populações idosa e pessoas desfavorecidas, na formação de uma sociedade inclusiva. Assim, precisa-se melhorar a comunicação entre os profissionais e unir pessoas em busca de um mesmo propósito (RIBEIRO; FERRAZ, 2016).

Já na quarta, a Academia da Saúde, oferta ações junto com a secretaria e unidades básicas de saúde em diferentes locais como condomínios, espaços voltados às 
práticas de atividades físicas direcionadas para os aspectos físico e mental do idoso proporcionando melhor qualidade de vida. O projeto tem mais de 142 mil usuários e está presente em 202 unidades de Atenção Primária (clínicas da família e centros municipais de saúde) que desempenham um conjunto de atividades já citada.

O trabalho coletivo desempenhado pela equipe multidisciplinar nas unidades de saúde contribui para um atendimento mais integrado com os usuários do programa. Essa parceria dos profissionais facilita a comunicação entre as áreas do saber que articulam um plano de trabalho para atingir o mesmo propósito. A correlação entre o trabalho educativo, o lócus territorial e os usuários do serviço, com a mediação dos profissionais de saúde, podem potencializar a aprendizagem dos envolvidos independente da faixa etária, quando a perspectiva da proposta caminha para campo reflexivo de caráter dialógico entre o mundo interno e externo (SILVA; SCHRAIBER; MOTA, 2019).

Na quinta, a Terceira e Idade e Movimento, ocorre por meio de ações indiretas socioeducativas e atividade lúdicas para convivência em grupo propiciando o desenvolvimento pleno do público-alvo. Pode ter parcerias com o Ministério de Desenvolvimento Social e Secretarias Municipais de saúde, Educação e Cultura e Assistência Social, para proporcionar melhor atenção a qualidade de vida das pessoas idosas.

As ações comunitárias para auto-organização de pessoas idosas ajudam a legitimar a identidade de um grupo que, através das atividades socializadoras, informativas, recreativas e de acompanhamento sistemático à saúde, possibilitam a troca de saberes mediadas pelo processo contínuo de aprendizagem e interação colaborativa. Essas ações refletem na forma como o sujeito interpreta a realidade por refletir os diferentes aspectos relacionados as dimensões biopsicossociais. Logo, os programas/projetos supracitados apresentam propostas direcionadas às pessoas idosas que perpassam pelos aspectos socioeducativos, cognitivos, de lazer e saúde, associados a entidades públicas, federais e governamentais (GIL, 2006). 
Os profissionais da saúde que desempenham as atividades aparecem atrelados com abordagem multidisciplinar em todos os programas/projetos analisados com o propósito de promoção, prevenção, socialização, fortalecimento de vínculos e integração intergeracional, para os usuários dos serviços. Assim, percebe-se que o mapeamento estruturado traz algumas possibilidades enveredadas nos referidos programas/projetos, que podem ser implantadas na cidade a partir da iniciativa de profissionais da saúde associados a entidades parceiras ampliando o leque de possibilidades para um envelhecimento ativo.

\section{CONSIDERAÇÕES FINAIS}

Essa pesquisa mostrou a importância da comunicação e das ações desenvolvidas pelos profissionais da saúde no trabalho coletivo associadas às pessoas idosas na perspectivada saúde ampliada. Essa evidencia nos leva a refletir a necessidade de fomentar políticas de atenção à saúde, bem como, aderir projetos/programas já existentes para atender uma demanda crescente da população.

O objetivo em questão foi alcançado pela sistematização do quadro síntese que propiciou discussões acerca dos profissionais de educação física que atuam com pessoas idosas. A partir dos programas analisados, foi possível compreender que os profissionais atuantes em programas direcionados a pessoas idosas desempenham um conjunto de atividades na perspectiva da promoção e prevenção da saúde que já são pré-definidas em projetos estruturantes associados a entidades públicas como prefeituras, órgão federais e governamentais. Correlacionando a reflexão analítica do estudo, nos atentamos aos cuidados que precisam ser considerados na implantação/criação dessas políticas com a realidade local.

Ao implantar um projeto/programa de pessoas idosas por entidades já mencionadas, precisa-se ater às diretrizes que regem a proposta para manter a essência idealizada, mas adaptar ao cenário local para que haja impacto, abrangência e aderência, pois, existem particularidades que são locais e regionais. Isso exige 
atenção da gestão que gerencia e acompanha os programas/projetos e os profissionais que as executam. Se esses fatores forem desconsiderados, podem comprometer as políticas no campo do planejamento, descentralização e implantação das propostas pelo distanciamento com o cenário real. Independentemente da idade cronológica e/ou biológica, é necessário contribuir para uma melhor qualidade de vida balizadas no compromisso e responsabilidade para que haja transformação social em todos os níveis.

\section{REFERÊNCIAS}

ALCÂNTARA, A. O, CAMARANO, A.M, GIACOMIN, K. C. Política nacional do idoso: velhas e novas questões. Rio de Janeiro: Ipea, 2016. ISBN 978-85-7811290-5.

BATISTA, Maique dos Santos Bezerra.; BATISTA, Rosana de Oliveira Santos. Práticas Corporais com Metodologias Ativas: o processo de fortalecimento e vínculos das pessoas idosas no município de Simão Dias/SE. In: Cenários e perspectivas da educação física: educação, saúde e lazer. - Paripiranga-BA: Faculdade AGES, 2021. E-book. P. 70-8. ISBN: 978-65-994411-0-3.

BEAUVIR, S. 1908 -1986. A velhice. tradução maria helena franco martins. 3 ed. Rio de Janeiro: nova fronteira. 2018. [recurso eletrônico - e-book] isbn 9788520943618.

BRASIL. Constituição da República Federativa do Brasil. Brasília, 1988.

BRASIL. Ministério do Desenvolvimento Social e Combate à Fome (MDS). Serviço de Convivência E Fortalecimento de Vínculos (SCFV). Secretaria Nacional De Assistência Social (SNAS), Departamento de Proteção Social Básica (DPSB). Brasília, 10 de julho de 2017. 
CAMARANO, Ana Amélia.; KANSO, Solange.; FERNANDES, Daniele. BRASIL ENVELHECE ANTES E PÓS-PNI. In: ALCÂNTARA, Alexandre de Oliveira.; CAMARANO, Ana Amélia.; GIACOMIN, Karla Cristina. Política nacional do idoso: velhas e novas questões. Rio de Janeiro: Ipea, 2016. ISBN 978-85-7811-290-5.

FERRARINE, Rosane de Fátima. Terceira idade e movimento, Campina Grande do Sul, 2011.

GIL, C.R.R. Atenção primaria, atenção básica e saúde da família. Sinergias e Singularidade do Contexto Brasileiro. Londrina (PR); 2006.

GIL, Antonio Carlos. Métodos e técnicas de pesquisa social. 6. ed. - São Paulo: Atlas, 2008.

IBGE. Instituto Brasileiro de Geografia e Estatística. Projeção da população do Brasil e das Unidades da Federação. Disponível em https://www.ibge.gov.br/apps/populacao/projecao/index.html. Acessado em12/03.2020.

OLIVEIRA, Talita Soares de.; SANTIAGO, Maria Luci Esteves.; FILHO, Luiz Antonio Silva Figueiredo. LEITINHO, Meirecele Calíope. O profissional de educação física atuando no sistema único de saúde: dificuldades e suas estratégias de superação. Braz. J. of Develop., Curitiba, v. 6, n. 6, p.37687-37699, jun. 2020.

RIBEIRO, S. FERRAZ, E. M. Programa Esporte e Lazer da Cidade: autogestão em foco. Corpoconsciência, Cuiabá-MT, vol. 20, n. 02, p. 10-22, mai./ago., 2016.

SILVA, Marcelo José de Souza.; SCHRAIBER, Lilia Blima.; MOTA, André. O conceito de saúde na Saúde Coletiva: contribuições a partir da crítica social e histórica da produção científica. Physis: Revista de Saúde Coletiva, Rio de Janeiro. 2019. 
VERAS, R. P, OLIVEIRA, M. O. Envelhecer no Brasil: a construção de um modelo de cuidado. Ciênc Saúde Coletiva. 2018; 23(6):1929-3.

Enviado: Abril, 2021.

Aprovado: Agosto, 2021. 